\title{
Instantiating the creation process in digital art for serious games design
}

\author{
Adérito Marcos ${ }^{\mathrm{a}, \mathrm{c}, *}$, Nelson Zagalo ${ }^{\mathrm{b}}$ \\ a engageLab/Algoritmi, University of Minho, 4800 Guimarães, Portugal \\ b engageLab/CECS, University of Minho, 4700 Braga, Portugal \\ ${ }^{\mathrm{c}}$ LEaD, Laboratory of Distance Education, Portuguese Open University, 1269-001 Lisbon, Portugal
}

\section{A R T I C L E I N F O}

\section{Article history:}

Received 16 September 2010

Revised 12 November 2010

Accepted 2 December 2010

Available online 22 December 2010

\section{Keywords:}

Digital art

Serious games

Creation process cycle

Aesthetic musing

Artefact

\begin{abstract}
A B S T R A C T
The creation process in digital art relies often on collaborations between an artist (or group of artists) and a multidisciplinary team. This collaboration implies a multidisciplinary work involving art, science, technology, design, psychology, etc. that come together by sharing a common communicational and informational space.

In this essay we bring into discussion how the creation process cycle in digital art could be instantiated and applied for the development of serious games through end-user purposes of both creative authors: the digital artists and the serious games developers. We realise a comprehensive analysis of this creation process in digital art, specially the aesthetic musing activity, while devising how it could be helpful to introduce new engaging stimulus in the creative process of serious games.
\end{abstract}

(c) 2010 International Federation for Information Processing Published by Elsevier B.V. All rights reserved.

\section{Introduction}

The process behind the act of the art creation or the creation process has been the subject of much debate and research during the last 50 years at least, even thinking art and beauty has been a subject of analysis already by the ancient Greeks such were Plato or Aristotle. Duchamp in his lecture "The Creative Act" [1] states the artist is never alone with his/her artwork; there is always the spectator that later on will react critically to the work of art. If the artist succeeds in transmitting his/her intentions in terms of a message, emotion or feeling to the spectator then a form of aesthetic osmosis actually takes place through the inert matter (the medium) that enabled this communication or interaction phenomenon to occur. The role of the spectator may become gradually more active by interacting with the artwork itself possibly changing or becoming a part of it [2-4].

Indeed, the creation process in digital art, taking here in a broad way embracing all kind of computer or electronic art, relies often on collaborations between an artist (or group of artists) and a multidisciplinary team of programmers, technicians, engineers, scientists and designers, among others. This collaboration implies a multidisciplinary work involving art, science, technology, design, psychology, etc. that come together by sharing a common commu-

\footnotetext{
* Corresponding author at: LEaD, Laboratory of Distance Education, Portuguese Open University, 1269-001 Lisbon, Portugal. Tel.: +351 213141 508; fax: +351 213 150183.

E-mail address: marcos@univ-ab.pt (A. Marcos).
}

nicational and informational space. Due to the widespread of the digitally coded information content that is increasingly available in high expressive multimedia formats, the creation process is becoming more and more based on the manipulation and integration of digital content for the creation of artworks [5].

The creation process in digital art is mainly based on the design of the artifact's message and its development. The computer medium in the form of editing, communication and collaboration tools as well as digitally coded information content is likely to be always present and traversing the overall creation process. The meaning of design in this context, appoints to a conscious effort to create something that is both functional and aesthetically pleasing. Design is here taken from both the perspective of design in engineering and from a more inventive view as it is the case in applied arts $[6,7]$. However, unlike in the pure design process, where the problem-solving guides the action of the designer, in digital art such systematic manner appears not primarily to solve a problem but to enhance the intention to the realization, i.e., the final artefact.

Generally, artists follow a similar process in developing their creative ideas, thought they may be less conscious of the process they are following. Initially the artist will tend to experiment in a rather random manner, collecting ideas and skills through reading or experimentation. Gradually a particular issue or question will become the focus of the experimentation and concrete implementation, formulating alternative ways, trying them, in order to adopt a refined one that will be pursued through repeated experimentation. Thus the design process itself evolves from a vision or idea/ concept (even if it is not aware for the creator) until the final digital 
artefact is released. The message the spectator can obtain from the artefact in terms of a personal or group experience is the central issue the digital artefact holds [8,9].

In this essay we bring into the discussion how this creation process cycle in digital art could be instantiated and applied for the development of serious games though end-user purposes of both creative authors - the digital artists and the serious games developers - differ in terms of the final end-user objective of their targeting outcomes. Serious games' developers concentrate in the digital story, the excitement of their final work on side of the end-user and their related functionalities to achieve it. Aspects such as easy-to-learn features, great end-user satisfactoriness are important (and pivotal). Digital artists are most of the time focused on their own satisfaction as creative persons while only secondly taking into consideration their artwork acceptance throughout a certain public. However, more and more digital artist have also to take into account, very seriously, in their creative work the end-user dimensions if they want to succeed as artists. As mentioned before, the creation process tends to focus in the message or experience the spectator (end-user) might be able to perceive/ experiment when manipulating/acting with the final artwork $[10,11]$. This is somehow similar to what is anticipated/expected with a serious game. How can the models, principles, strategies and technologies, as also, best practices of both areas be merged or explored jointly? We ought in this article to analyse the intrinsic design/development process of both areas and devise a common framework for creative artefacts being these digital artworks, serious games or any other object resulting from a creation process (e.g. graphic design).

This essay is organized in the following sections: first we describe the creation process in the digital art as we perceive and apply it from the message design and technological development point of views. Then we describe the traditional development cycle of serious games. In Section 4 we describe a vision for a common framework for creative development in digital art and serious games which is mainly based on exploring the aesthetic musing activity. Finally we draw out some conclusions.

\section{The creation process in digital art}

The creation process relies mostly on creative design process with several phases starting from the first concept until the final artefact is released into exhibition.

As depicted in Fig. 1 the creative design process is launched when the artist gets hold with an initial idea/concept. This process is not a linear process, i.e., artists may go back and further in the activity sequence, skipping one or focusing the work in another. The process is usually highly dynamic, yet, the artist's vision is always present [12].

There are different phases of the creation process each one covering an important aspect of the formation of the final artefact. These different phases are described in following:Message design phase:

- Concept design: In this activity the artist gets involved in converting his/her idea/concept or vision into a set of sketches, informal drawings, i.e., the abstraction is concretized in a perceptive structure. The artist does exploratory drawings that are not intended as a finished work. The outcomes of this activity are, thus, sketches, drawings that allow the artist to try out different ideas and establish a first attempt for a more complex composition.

- Narrative design: Here the artist takes the drawings resulting from the concept design activity and designs a composition, a construct of a sequence of events that set up the message that will allow the users/viewers an emotional connection which grants memories and recounting of the artwork. The narrative

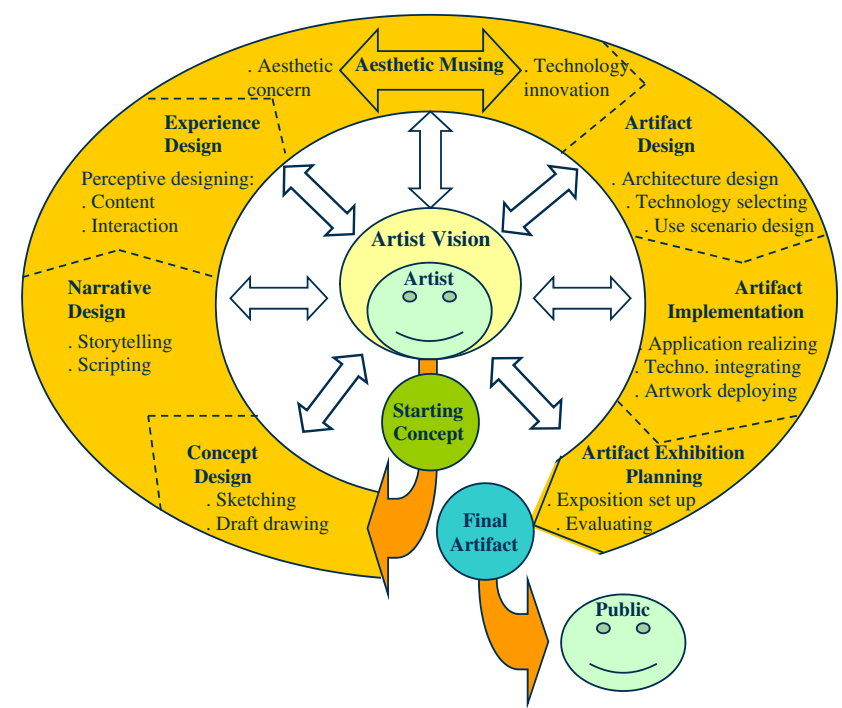

Fig. 1. Overview of the different phases of the creation (or creative design) process in digital art.

of the message behind the initial concept is designed taking into consideration aspects such as the structure of its constituent parts and their function(s) and relationships. The narrative assumes the form of a chronological sequence of themes, motives and plot lines. The outcome of this activity can be resumed as the design of the message as a story.

- Experience design: This activity embraces the process of designing the message, taking into account its related concept and narrative, to design and conceptualize specific characteristics of each narrative event from the point of view of the human experience it shall provide. This design or planning of the human experience is made based on the consideration of an individual's or group's needs, desires, beliefs, knowledge, skills, experiences, and perceptions. The experience design attempts to draw from many sources including cognitive and perceptual psychology, cognitive science, environmental design, haptics, information content design, interaction design, heuristics, and design thinking, among others.

Aesthetic musing: This is a central activity in the creative design process, it represents the moments of contemplation where the artist revise his/her vision against the decisions made (to be done) (see Fig. 2) during the design and development of the artefact. We identify two guiding vectors in aesthetic musing of artefacts.

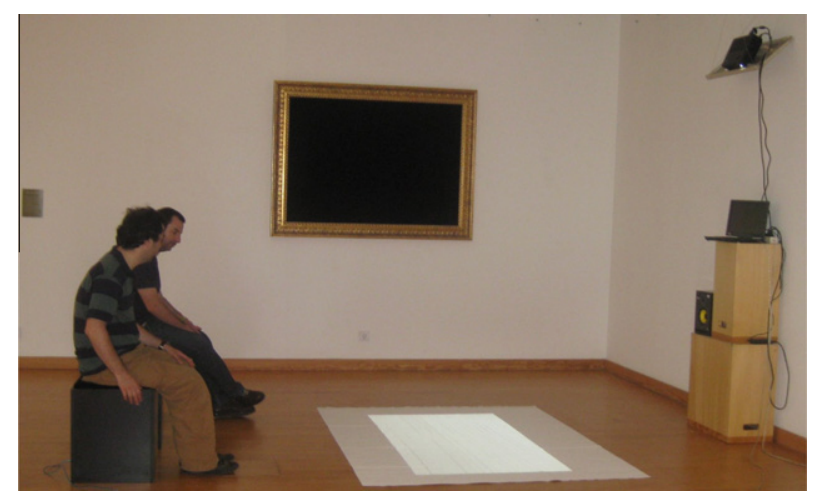

Fig. 2. Digital artists during creative development (artefact: "Gato, o novo flâneur” by Raquel Pinto \& Filipe Leite) (Courtesy of the Master Course in Technology and Digital Art of the University of Minho, Portugal). 
- Aesthetic concern: Process of integrating characteristics in the artefact that eventually provide a perceptual experience of pleasure, meaning or satisfaction, arising specifically here from sensory manifestations of the artefact such are shape, colour, immersion, sound, texture, design or rhythm, among others. Beauty here relates almost exclusively to the aesthetic dimension of the perceptive nature of the artefact components.

- Technology innovation: Process of integrating novelty in the reshape, use, combination and exploitation of digital technology. This appoints to the computer medium dimension of the aesthetic creation, i.e., the technology is a driven force to set up new aesthetic dialogues. Taken the fact of the digital technology is under accelerated development; integration of high levels of technology innovation in digital art is commonly desired.

Artefact development phase (see Fig. 3)

- Artefact design: This activity relates to all aspects concerned with the design of the computer system or application that will support the final artefact. This includes the design of the system architecture, interface and interaction, as well as the selection of technology to implement them. Since the artefact is to be acted usually by an audience of viewers, we have also considered in this activity the design of the use scenario from the technological point of view. Design adopts here a hybrid perspective mixing aspects from applied arts and engineering. It applies principles from a more rigorous design based on exploitation of technology, science and even mathematical knowledge along with the aesthetical concerns.

- Artefact implementation: In this activity the artist proceeds to the implementation of the artefact itself. This incorporates tasks as programming, testing and debugging, as well as, technology integration and the final artefact deployment. This demands from the artist to hold programming and technological skills if he/she wants to have a more direct control over the implementation process. The artist can even be assisted by a team of programmers and technologists; however, to be in command of the artwork, the artist has to be skilled in technology to a certain level.

- Artefact exhibition planning: This activity joins together all aspects related with the setting up of the artefact exhibition. This represents the final stage of the overall creative design process, where the artefact is brought into the world, i.e., the art object meets the audience. The success of this meeting will

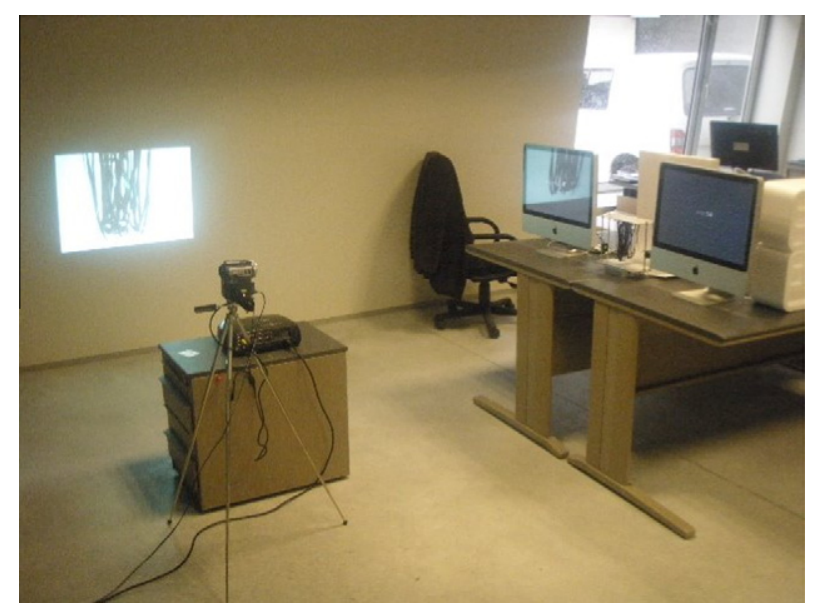

Fig. 3. Overview of the final artefact and its own development environment (artefact: "Breeze" by Sofia Oliveira \& Vitor Lago) (Courtesy of the Master Course in Technology and Digital Art of the University of Minho, Portugal). depend increasingly on the attractiveness of the artefact, the way the exhibition space is organized, how the logistic of its different components are managed and supported and also on the contextualization of the artefact in the overall exhibition. Notice this activity will be based on the decisions made before in terms of the message design, the artefact implementation, and above all, on the use scenario configuration. Artefacts may be presented in museums, art halls, art clubs or private art galleries, or at some virtual place such is the Internet.

The creation process in digital art has a propensity to focus in the message or experience the observer or art consumer might be able to perceive/experiment when manipulating/acting with the final artefact. This is somehow similar to what is anticipated/ expected with a serious game.

In the following section we present the approach followed by serious games to construct a different type of experience taking into account its specific goals.

\section{Serious games approach}

In this decade, games and interactive media have been accused of doing bad [15-17] and good [18,19] according to two different perspectives on social impacts. Books and reading still possess strong values, unreachable for film or games, just as film and games enable experiences that are inaccessible to books.

In literature, the main goal of the writer is to tell the narrative in the greatest detail in order to develop a strong fabula or mental story in the receptor's mind. In film, the narration gains new media terrains by making it possible to show instead of tell [20]. Film does not need to spend time explaining details because they are shown. The story world comes ready-built to the receptor, proposing direct perception of the visual world that enhances perceptive emotions and so, learning. With games, storytelling activates a complete new set of cognitive activities and learning possibilities. The story is no longer an act of telling, or showing but an integrated set of active participations, of doing. Games media open a new space (virtual) for the mediation of knowledge, for the enhancement of knowledge construction in the receptor, through the well-known mode of learning by doing processes of inference on the part of the receptor, processes that involve active and associative thinking [21]. We make sense of the world through patterns that help us in the associative process of finding the right concept in our brain database [22]. When we see someone in a film scene entering an elevator, and in the next scene coming out of the elevator, we mentally fill in what happened between the two scenes with our assumptions; we do not ask what happened, or where the character comes from. The same happens for almost all missing information, or information deliberately not given to the receptor to create an active hypothesis testing process [21]. In this process, we elaborate various hypotheses to supply the missing information and we test them mentally throughout the process of storytelling until each hypothesis is proved or disproved. So, it is not difficult to understand the involvement required to answer correctly the hypotheses our brain poses when reading a book, seeing a film and playing a game. In each of these media we use the exact same process, the difference is in the amount of information given or not given to the receptor. In a book, if the author does not say the sun is shining or if the sky is gray, the reader will have to create a mental image choosing to depict a sunny or gray day through the process of hypothesing in accordance with other cues picked up in the text. In film and games, the day is sunny or gray and is actually represented in the scene. Also, when it comes to understanding the effect of how to perform some action, such as driving a car in a robbery, the reader will have to call on all his imagination to give 
life to the scene, bring together all his previous moments of tense driving, with possible scenes of movies and games, to establish hypotheses about streets, signals, obstacles, buildings, etc. On the other hand, games' conveyance of the message is almost direct, with almost identical physical sensations through visuals, sounds and touch (with the driving wheel) requiring little imagination from the player to recall those tense driving moments. Having discovered the potential in games for transmitting knowledge, researchers of game education then followed the serious games route. This serious route has been applied addressing only slightly player enjoyment and entertaining value putting the emphasis on teaching and transmitting specific sets of learning messages, independently of the structure, form and gameplay used. As we can see by definition, serious games "aim at providing an engaging, selfreinforcing context in which to motivate and educate the players" [23], which explains the serious label. The goal is to reinvent learning in school "more game-like in the sense of using the sorts of learning principles that young people see in good games every day" [24]. Or as Shaffer et al. [25] put it: "We need to leverage these understandings to build games that develop for players the epistemic frames of scientists, engineers, lawyers, and other valued communities of practice".

This kind of research approach looks at games as a kind of magic powder for education. Nine years ago, Microsoft engaged with the Comparative Media Studies group at the MIT to develop the Games-To-Teach project and in the launch statement read: the Games-To-Teach Project hopes to offer students a chance to explore the worlds of math, science, and engineering through new and exciting game models. The results of this project were summarized in the paper Design Principles of Next-Generation Digital Gaming for Education [26] presenting superficially seven principles for the creation of games to teach. This is nothing new. In the 1990's with the appearance of the CD-ROM and more complex games graphics we had another boom in interest in creating games for learning and then labelled interactive edutainment. As argued by Ref. [27], edutainment goes back to the 1980's, and since then, if we look back at the overall research on the subject, "it has to be said that the current findings on learning outcome are positive and promising. Some scepticism is warranted, however, because the lack of control groups, researcher bias, weak assessment tests, and short exposure time is not addressed sufficiently". The beginning of this century saw a decline in interest in this segment of games [28] due to the identification of certain problems: the short duration of lessons to envelop game experiences; physical space; students' game competences and teachers' preparation [27]. The lack of confidence in research results and decline in edutainment user motivation led Egenfeldt-Nielsen to work with serious games. However, the question remained unanswered and [29] synthesizes this in the following example: "In geography - which is all but ignored these days- there is no reason that a generation that can memorize over 100 Pokémon characters with all their characteristics, history and evolution cannot learn the names, populations, capitals and relationships of all the 101 nations in the world".

In our perspective, the problems related to edutainment stated by Egenfeldt-Nielsen are still valid in the serious games approach, when specifically talking about using them in schools. This is a motivational question more than anything, and Prensky recognizes this. Nevertheless, we believe that we can learn with games. Games are very good for training because games are grounded in play, one of the most ancient's forms of learning. Also play uses as central motor the act of pretending which is connected to our use of simulation. Simulation is one the best ways to train - just ask airplane pilots, fire workers - (see Fig. 4).

However, simulation does not work if there is no motivation, and even worse, it does not work in all domains. Games and simulations are good for training external actions, as acknowledged

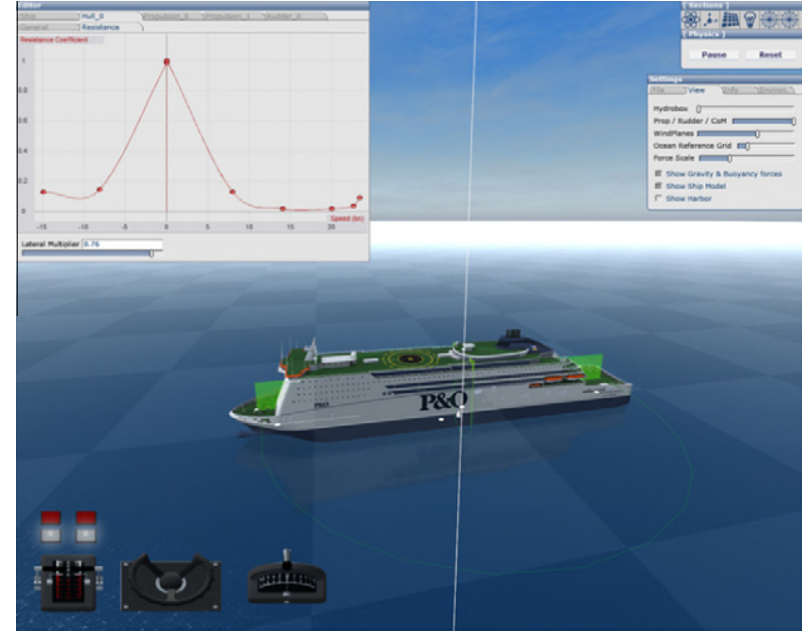

Fig. 4. Ship simulator professional (2007).

by Gee in the importance of video games as "action-and-goal directed simulations of embodied experience", and as argued by Prensky in relation to the success of learning, "Practice -time spent on learning- works". Both views are true and exemplify the problem we have, that not everything can be learned through external practice. The question is how to build a $3 d$ action game or simulation to reach the depths of interpretation we reach by reading the poetry of Fernando Pessoa, the speech by Socrates on his suicide or even Kubrick's “2001: A Space Odyssey” (1967) or Tarkovsky's "Solyaris" (1972).

Interactive devices, such as games and simulations, are bad at portraying drama, melancholy and the depths of the human condition in general [30]. Games are good at teaching external abstractions like math and physics but bad at representing introspection and philosophy.

This explains why we intend to bring different creation models into the developing of serious games artefacts, and more in concrete models from the digital arts domain. The goal is really to extract motivation, inspiration and engagement from the momentum created in the relation between the digital artefacts and users.

We believe that serious games can gain new and valuable dimensions if allowed to transpire its inherent artistic values in concrete the ones related to player enjoyment. It cannot continue to be only a question of transmitting a message and forgetting motivation but it must be also an experience of pleasure created for the user. As with digital art, the goal must be to unify meaning and sensory manifestations.

\section{Aesthetic musing in serious games design and development}

The main problem with the process of serious game creation when compared with the digital arts process relates to the too much weight put on the Message Design phase as opposed to an almost absent Aesthetic Musing phase. In terms of the Artifact Development they would be in similar lines. Then while we still believe that concept and narrative merits great emphasis because of the specific goals of serious games we believe that adding elements of Aesthetic Musing from digital arts into the process of development of serious games would be helpful.

Aesthetic musing in digital art creative design process represents a central activity. The artist or creative person realises aesthetic musing when he/she enters into mental contemplation or reverberation about the inner and most profound reasons/meaning of the intended artefact, how it can work as an intervention tool in 
society and history. Visions are generated that may shape and reshape again the evolving and development of the emerging artefact, giving sense of (in) coherence and meaning to the artefact and its message/story.

Aesthetic musing means create mechanisms to inquiry the world through an ongoing process of interacting with the artefact to (re)create additional and/or enhanced meanings. Aesthetic musing can bring into the serious game design process the dimension of the aesthetic motivation not only for designers but also and specially for end-users. Aesthetic musing means here giving emphasis to artefact aspects concerning about the perceptual experience of pleasure, meaning or satisfaction, the sense of beauty, the level of reverberation common to many contemporary artworks. Serious games may keep short in time, as short lessons, but become highly engaging by exploring the inner sense of pleasure or contemplation artworks affect, i.e., there occurs then a form of aesthetic osmosis.

On the other hand, aesthetic musing in the digital art creative design process also embraces a kind of search for technology innovation, i.e., the creative designer/developer enters a process of integrating novelty in the reshape, use, combination and exploitation of digital technology looking for new aesthetic dialogues, vectors of exploration that opens doors to new perceptive and ultimately, artistic experiences.

We believe that for serious games the contemplation within the technology innovation must be more focused than in digital art. Creators need to push boundaries of the design of game mechanics [13]. Mechanics stands in games for the way users are allowed to interact and play with the game. They put in perspective founding elements of the game: goals, attributes, actions and skills [13]. Then it is up to the designer to create a sufficiently entranced structure capable to support the entire player interaction.

In this phase of the process, the aesthetic musing is not anymore a question of transmitting the message or information to be learned only but instead to stimuli the player judgment into accepting the concept. For Kant [14] the contemplation of beauty was a judgment that needed to affect sensory, emotional and intellectual at once. We consider that holding such characteristics can create moments of individual and collective reflection, cognitive introspections that may transform the act of playing and learning.

In the Fig. 5 we propose an instantiation of the creative design process in digital art (see Fig. 1) to serious game design and development. As we can state both creative design processes are slightly similar thought in emphasis as to be put in the aesthetic musing in both cases.

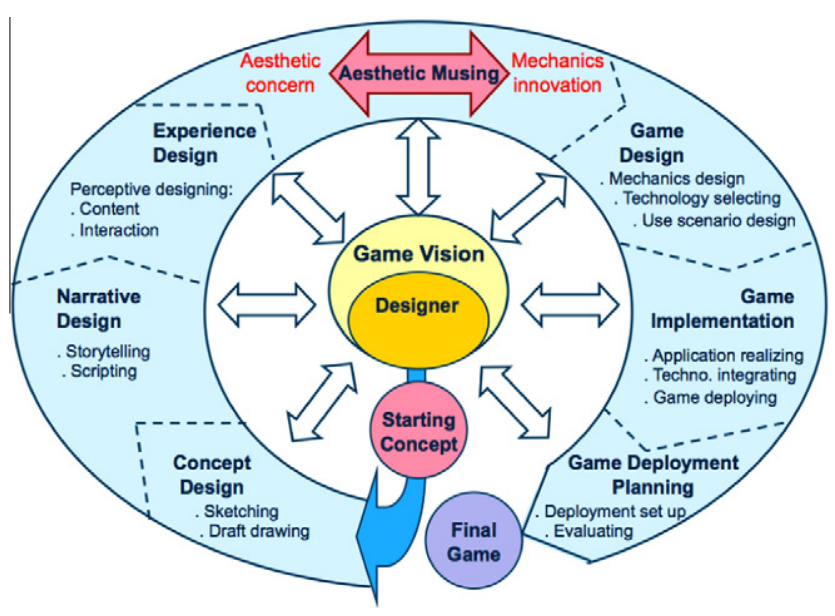

Fig. 5. The creative design process in digital art instantiated to serious game design and development.
In this instantiation we can analyse the impact of aesthetic musing, absent from regular serious games design, as affecting more two phases of the creation process: "experience design" and "game design". For the "experience design" we will have now a filter related to "aesthetic concerns", which means, the experience we will have to be designed taking into account the pleasure of the user. As for the game design itself the "mechanics innovation" become prior before starting the process of design. Mechanics are the central motor of game expression, and then pushing boundaries for innovation through the necessary steps of musing will take serious game to another level of interest for the user. Innovative mechanics will attract players to play for the game itself, and without even realizing they will be taken through the messages and meaning that serious games needs to convey.

\section{Conclusions}

In this essay we have discussed and developed a new model of creation to optimize the development of serious games taking into account specifically the process occurred in the digital arts domain by giving special emphasis on aesthetic musing.

We could discuss and argue against this convergence, and plead instead for a use of the creative processes behind successful commercial games. However as we discussed throughout this paper there are problems surrounding capabilities of serious games, and games in general, in relation to the use and communication of specific themes and topics.

Thus we believe that serious games can benefit immensely from this convergence related to creation practices. Having particular and different goals, serious games and digital arts share the same need for an engaged and valuable user experience. Bring into serious games aesthetic musing aspects may help end-users to enter mental contemplation or reverberation process about the concept and knowledge the game transmits thus transform its playing into a profound cognitive and philosophic experience.

\section{References}

[1] M. Duchamp, The Creative Act, Lecture at the Museum of Modern Art, New York, 1959, October 19, 1961, Published in Art and Artists, 1, 4 (July 1966).

[2] U. Eco, The Open Work, Harvard University Press, 1962, 1989.

[3] T.S. Eliot, Tradition and Individual Talent in the Sacred Wood; Essays on Poetry and Criticism, Methune, London, 1920, ISBN:1-58734-011-9.

[4] O. Grau, Virtual Art - From Illusion to Immersion, The MIT Press, Cambridge Massachusetts, 2003.

[5] R. Greene, Internet Art, Thames \& Hudson Ltd., London, 2005.

[6] B. Laurel (ed.), Design Research: Methods and Perspectives, The MIT Press, 2003.

[7] J. Löwgren, E. Stolterman, Thoughtful Interaction Design - A Design Perspective on Information Technology, The MIT Press, Cambridge, Massachusetts, 2007.

[8] A. Marcos, Digital art: when artistic and cultural muse and computer technology merge, IEEE Comput. Graphics Appl. 5 (27) (2007) 98-103.

[9] A. Marcos, P. Branco, J. Carvalho, The computer medium in digital art's creative development process, in: James Braman, Giovanni Vincenti (Eds.), Handbook of Research on Computational Arts and Creative Informatics, IGI Publishing, 2009.

[10] Ch. Paul, Digital Art, Thames \& Hudson Ltd., London, 2005.

[11] P. Routio, Arteology, The Science of Artifacts, University of Arts and Design Helsinki (UIAH), 2007, <http://www2.uiah.fi/projects/metodi/108.htm> (visited at 01.02.09).

[12] S. Wilson, Information Arts: Intersections of Art, Science, and Technology, The MIT Press, Cambridge, Massachusetts, 2002.

[13] Schell, Jesse, The Art of Game Design A Book of Lenses, Morgan Kaufman Publishers, Elsevier, Burlington, USA, 2008.

[14] Kant, Immanuel, Observations on the Feeling of the Beautiful and Sublime (Trans. John T. Goldthwait), University of California Press, 1961, 2003

[15] National Endowment for the Arts (NEA), Reading at Risk: A Survey of Literary Reading in America, 2004, <http://www.nea.gov/pub/ReadingAtRisk.pdf>.

[16] Rich, Motoko, The Future of reading, Literacy Debate: Online R U Really Reading? New York Times, 2008.

[17] Macintyre, Ben, The internet is killing storytelling, The Times, 2009, <http:// www.timesonline.co.uk/tol/comment/columnists/ben_macintyre/ article6903537.ece>. 
[18] J.P. Gee, What Video Games have to Teach us about Learning and Literacy, Palgrave Macmillan, New York, 2003.

[19] Johnson, Steven, Everything Bad is Good for You, Penguin Books, London, England, 2005.

[20] Mamet, David, in: On Directing Film, Penguin, US, 1992.

[21] D. Bordwell, Narration in the Fiction Film, University of Wisconsin Press, Madison, WI, 1985.

[22] Koster, Raph, A Theory of Fun for Game Design, Paraglyp Press, Arizona USA, 2005.

[23] M. Kankaanranta, P. Neittaanmäki (Eds.), Design and Use of Serious Games, Intelligent Systems Control and Automation: Science and Engineering, vol. 37, Springer, Dordrecht, 2009.

[24] J.P. Gee, Good video games and good learning, Phi Kappa Phi Fórum 85 (2) (2005) 33-37.
[25] D.W. Shaffer, K.D. Squire, R. Halverson, J.P. Gee, Video games and the future of learning, Phi Delta Kappan 87 (2) (2005) 104-111.

[26] K. Squire, Games-to-Teach Team, Design principles of next-generation digital gaming for education, Educational Technology 43 (5) (2003) 17-33.

[27] Egenfeldt-Nielsen, Simon, Overview of Research on the Educational Use of Video Games in Digital Kompetanse, vol. 1, 2006, pp. 184-213.

[28] Prensky, Marc, The Emerging Online Life of the Digital Native, published in Prensky website, 2004, <http://www.marcprensky.com/writing/PrenskyThe_Emerging_Online_Life_of_the_Digital_Native-03.pdf $>$.

[29] Prensky, Marc, Digital Natives Digital Immigrants in On the Horizon, vol. 9(5), MCB University Press, 2001.

[30] N. Zagalo, Convergência entre o Cinema e a Realidade Virtual (Convergence between Film and Virtual Reality), PhD Thesis, Departamento de Comunicação e Arte Universidade de Aveiro, Portugal, 2007 